NASA/TM-2000-209024

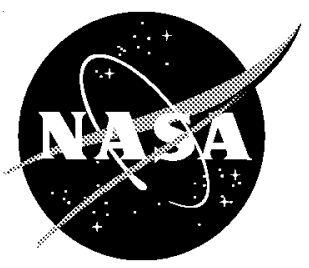

\title{
Flying Quality Analysis of a JAS 39 Gripen Ministick Controller in an F/A-18 Aircraft
}

John F. Carter and P. C. Stoliker

NASA Dryden Flight Research Center

Edwards, California 


\section{The NASA STI Program Office...in Profile}

Since its founding, NASA has been dedicated to the advancement of aeronautics and space science. The NASA Scientific and Technical Information (STI) Program Office plays a key part in helping NASA maintain this important role.

The NASA STI Program Office is operated by Langley Research Center, the lead center for NASA's scientific and technical information. The NASA STI Program Office provides access to the NASA STI Database, the largest collection of aeronautical and space science STI in the world. The Program Office is also NASA's institutional mechanism for disseminating the results of its research and development activities. These results are published by NASA in the NASA STI Report Series, which includes the following report types:

- TECHNICAL PUBLICATION. Reports of completed research or a major significant phase of research that present the results of NASA programs and include extensive data or theoretical analysis. Includes compilations of significant scientific and technical data and information deemed to be of continuing reference value. NASA's counterpart of peer-reviewed formal professional papers but has less stringent limitations on manuscript length and extent of graphic presentations.

- TECHNICAL MEMORANDUM. Scientific and technical findings that are preliminary or of specialized interest, e.g., quick release reports, working papers, and bibliographies that contain minimal annotation. Does not contain extensive analysis.

- CONTRACTOR REPORT. Scientific and technical findings by NASA-sponsored contractors and grantees.
- CONFERENCE PUBLICATION.

Collected papers from scientific and technical conferences, symposia, seminars, or other meetings sponsored or cosponsored by NASA.

- SPECIAL PUBLICATION. Scientific, technical, or historical information from NASA programs, projects, and mission, often concerned with subjects having substantial public interest.

- TECHNICAL TRANSLATION. Englishlanguage translations of foreign scientific and technical material pertinent to NASA's mission.

Specialized services that complement the STI Program Office's diverse offerings include creating custom thesauri, building customized databases, organizing and publishing research results...even providing videos.

For more information about the NASA STI Program Office, see the following:

- Access the NASA STI Program Home Page at http://www.sti.nasa.gov

- E-mail your question via the Internet to help@sti.nasa.gov

- Fax your question to the NASA Access Help Desk at (301) 621-0134

- Telephone the NASA Access Help Desk at (301) 621-0390

- Write to: NASA Access Help Desk NASA Center for AeroSpace Information 7121 Standard Drive Hanover, MD 21076-1320 


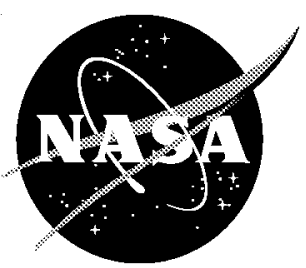

\section{Flying Quality Analysis of a JAS 39 Gripen Ministick Controller in an F/A-18 Aircraft}

John F. Carter and P. C. Stoliker

NASA Dryden Flight Research Center

Edwards, California

National Aeronautics and

Space Administration

Dryden Flight Research Center

Edwards, California 93523-0273 


\section{NOTICE}

Use of trade names or names of manufacturers in this document does not constitute an official endorsement of such products or manufacturers, either expressed or implied, by the National Aeronautics and Space Administration.

Available from the following:

NASA Center for AeroSpace Information (CASI)

7121 Standard Drive

Hanover, MD 21076-1320

(301) 621-0390
National Technical Information Service (NTIS) 5285 Port Royal Road Springfield, VA 22161-2171 (703) $487-4650$ 


\title{
FLYING QUALITY ANALYSIS OF A JAS 39 GRIPEN MINISTICK CONTROLLER IN AN F/A-18 AIRCRAFT
}

\author{
John F. Carter* and P. C. Stoliker ${ }^{\dagger}$ \\ NASA Dryden Flight Research Center \\ Edwards, California
}

\begin{abstract}
$\underline{\text { Abstract }}$
NASA Dryden conducted a handling qualities experiment using a small displacement centerstick controller that Saab-Scania developed for the JAS 39 Gripen aircraft. The centerstick, or ministick, was mounted in the rear cockpit of an F/A-18 aircraft. Production support flight control computers (PSFCC) provided a pilot-selectable research control system. The objectives for this experiment included determining whether the mechanical characteristics of the centerstick controller had any significant effect on the handling qualities of the F/A-18, and determining the usefulness of the PSFCCs for this kind of experiment. Five pilots evaluated closed-loop tracking tasks, including echelon and column formation flight and target following. Cooper-Harper ratings and pilot comments were collected for each maneuver. This paper describes the test system, including the PSFCCs, the Gripen centerstick, and the flight test experiment. The paper presents results of longitudinal handling qualities maneuvers, including low order equivalent systems, Neal-Smith, and controls anticipation parameter analyses. The experiment showed that, while the centerstick controller provided a different aircraft feel, few handling qualities deficiencies resulted. It also demonstrated that the PSFCCs were useful for this kind of investigation.
\end{abstract}

\section{$\underline{\text { Nomenclature }}$}

AC alternating current

CAP controls anticipation parameter

*Aerospace Engineer, Member AIAA.

$\uparrow$ Aerospace Engineer.

Copyright (C) 2000 by the American Institute of Aeronautics and Astronautics, Inc. No copyright is asserted in the United States under Title 17, U.S. Code. The U.S. Government has a royalty-free license to exercise all rights under the copyright claimed herein for Governmental purposes. All other rights are reserved by the copyright owner.

$\begin{array}{ll}\text { CHR } & \text { Cooper-Harper rating } \\ \text { CSA } & \text { control stick assembly } \\ \text { KCAS } & \text { knots calibrated air speed, nmi/hr } \\ K_{p} & \text { gain for compensation model, deg/deg } \\ K_{q} & \text { gain for pitch rate transfer function, deg } \\ L_{\alpha} & \text { lift due to angle of attack change, } 1 / \mathrm{sec} \\ \text { LOES } & \text { low order equivalent system } \\ \text { NOF } & \text { number of frequency points } \\ N z & \text { load factor, } g \\ \text { PSFCC } & \text { production support flight control } \\ & \quad \text { computers } \\ Q & \text { pitch rate, deg/sec } \\ s & \text { Laplace operator } \\ \text { SRA } & \text { Systems Research Aircraft } \\ T_{l a g} & \text { compensator lag time constant, sec } \\ T_{l e a d} & \text { compensator lead time constant, sec } \\ \text { VDC } & \text { volts direct current } \\ \alpha & \text { angle of attack, deg } \\ \Delta g a i n & \text { difference in gain between actual and } \\ \Delta & \text { LOES values, dB } \\ \Delta p h a s e & \text { difference in phase between actual and } \\ \zeta & \text { LOES values, deg } \\ \tau_{\text {comp }} & \text { short period damping } \\ \omega_{s p} & \text { pitch attitude, deg } \\ & \text { equivalent system time delay, sec } \\ \text { compensator time delay, sec } \\ \end{array}$




\section{$\underline{\text { Introduction }}$}

Over the years, many types of pilot control sticks have been used in fighter class aircraft. Each type has different mechanical properties, some of which have led to problems with aircraft operation. Early development of alternate controllers for fighter class aircraft demonstrated some difficulties with fixed, forcecommand sidestick controllers. ${ }^{1}$

The aircraft company Saab-Scania (Linköping, Sweden) designed a pilot control stick for the JAS 39 Gripen fighter/attack airplane. This stick is a smalldisplacement, position-command controller mounted in the center of the cockpit on a raised pedestal. This controller differs from the traditional F/A-18 control stick, which has large movement and pivots approximately at the floor of the cockpit. The center mounting of the Gripen control stick also ergonomically differs from the side-mounted force-command control sticks found in aircraft such as the F-16 and F-22 fighters.

NASA Dryden Flight Research Center conducted an experiment to determine whether the mechanical properties of the Gripen control stick would produce any change in handling qualities for an F/A-18 aircraft. For the experiment, NASA Dryden mechanics mounted the Gripen stick in the rear cockpit of an F/A-18B model. The Gripen stick interfaced with the F/A-18 aircraft with the use of the production support flight control computers (PSFCC). ${ }^{2} \mathrm{~A}$ quadruplex-redundant flight control computer system controlled the F/A-18. The PSFCCs are F/A-18 flight control computers with a research processor interfaced with all four channels. When selected, the research processors have full authority of all F/A-18 aircraft control surfaces. Each research processor allowed for direct analog input from an external device. The Gripen stick connected directly with the research processors via these analog inputs.

From February 23 to March 2, 1999, NASA Dryden conducted a brief flight-handling qualities test campaign consisting of six flights. During these six flights, five pilots evaluated both open- and closed-loop tasks. The performance of open-loop tasks qualitatively measured aircraft response with the Gripen stick. Open-loop maneuvers included doublets and frequency sweeps. Closed-loop maneuvers included bank angle captures, pitch attitude captures, echelon (wing) formation flight, column formation flight, and target following. To acquire Cooper-Harper ratings ${ }^{3}$ (CHR) and pilot comments, researchers developed adequate and desired criteria for each task. Data from the formation flight and target tracking were compared with selected handling qualities criteria.

Frequency responses of Gripen stick position to aircraft pitch rate were calculated from flight data and then fit to a low order equivalent system (LOES) approximation. ${ }^{4,5}$ This LOES analysis used a fixed lift due to angle of attack, $L_{\alpha}$, calculated from the NASA Dryden nonlinear F-18 simulation. Estimated aircraft parameters from the LOES were used in controls anticipation parameter $(\mathrm{CAP})^{5}$ and Neal-Smith analyses. ${ }^{6}$ These handling quality criteria were used to estimate flying qualities levels $(1,2$, and 3$)$ for the aircraft independent of the Gripen stick. These estimated ratings were compared with the actual pilot ratings. This paper discusses differences in the ratings in relation to pilot workload and the mechanical properties of the Gripen stick.

Use of trade names or names of manufacturers in this document does not constitute an official endorsement of such products or manufacturers, either expressed or implied, by the National Aeronautics and Space Administration.

\section{Aircraft and System Description}

\section{System Research Aircraft}

The flight test used the F/A-18B aircraft known as the Systems Research Aircraft (SRA) ${ }^{7}$ (fig. 1). NASA Dryden has used this two-seat aircraft for numerous flight experiments of advanced systems such as conformal load-bearing antennas, electric actuators, and in-flight Schlieren photography. This aircraft has an extensive research instrumentation suite along with telemetering capability. Because the Gripen controller was mounted in the rear cockpit, the front seat pilot, known as the safety pilot, performed all the engagement and disengagement tasks of the research processors.

For this experiment, the aircraft was equipped with PSFCCs. The PSFCC design uses a research processor in addition to the baseline quadraplex F/A-18 flight control computers. If the aircraft were to exceed certain performance limits or to suffer a system failure, the PSFCC would automatically disengage the research processor and revert to the baseline flight control system. The safety pilot also has the ability to manually disengage the research flight control system.

For this flight experiment, the research flight control laws replicated the F/A-18 baseline control laws using the Gripen stick pitch and roll commands in place of the standard F/A-18 control inputs. No other changes were 


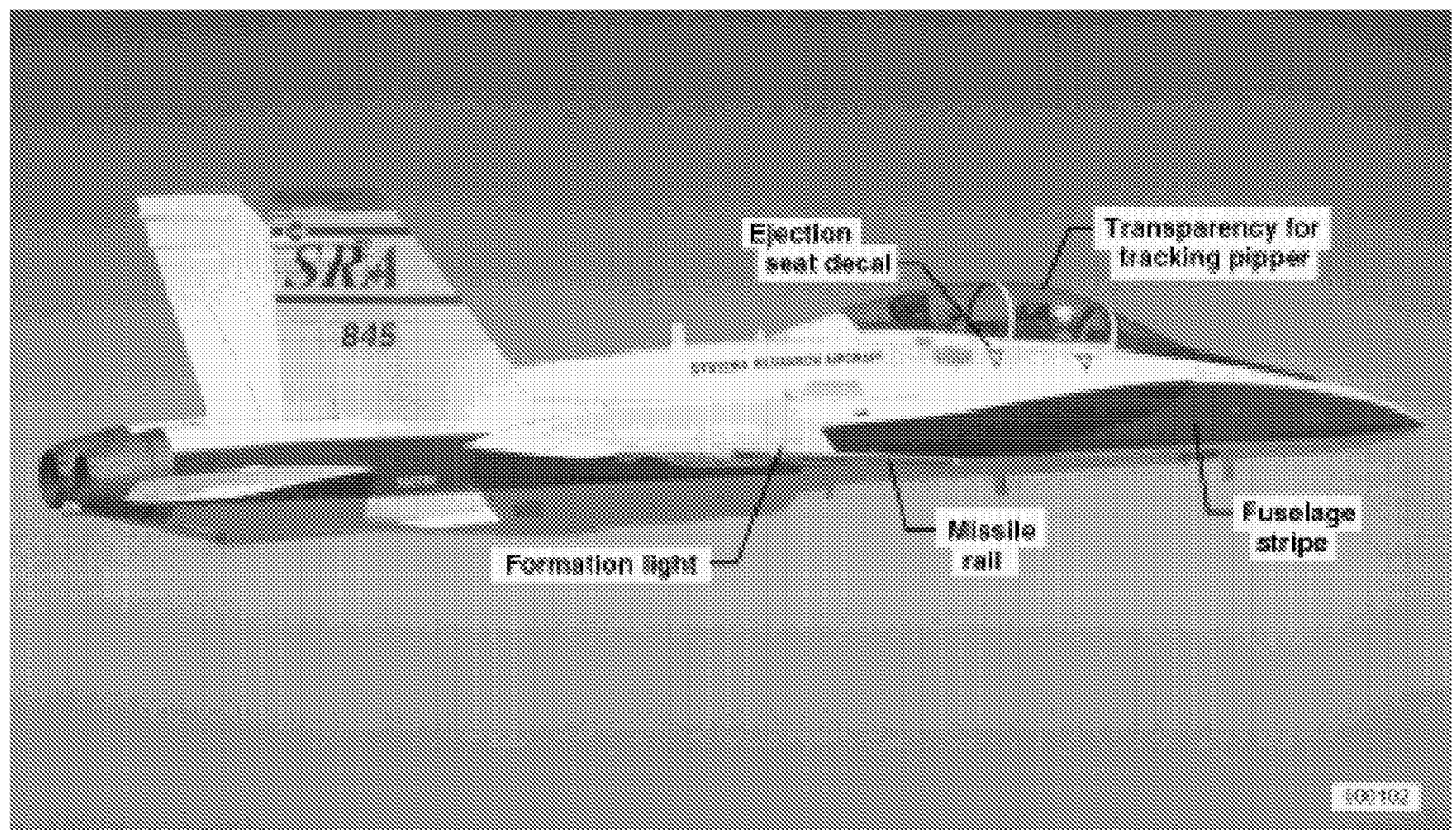

Figure 1. Systems Research Aircraft.

made to the baseline F/A-18 control laws, and the baseline F/A-18 stick shaping and software breakouts were used. Figure 2 shows the interface between the Gripen control stick and the PSFCCs in the SRA aircraft. The Gripen stick connects directly with the research processors. Shared memory called a dual-port random access memory, between the research processors and the baseline F/A-18 control law processors, received all other necessary information. This shared memory provided a separation between the two control system processors for fault isolation of the research processor. Previous publications ${ }^{2,8}$ show details on the operation of the PSFCCs.

\section{Gripen JAS 39 Control Stick Description}

Saab-Scania developed the control stick assembly (CSA) for the JAS 39 Gripen, a lightweight fighter aircraft. The CSA consisted of a fixed pedestal that housed the triplex redundant electronics, with a fighterstyle handgrip mounted on top. Unlike other small displacement or force controllers typically mounted to the side of the pilot, the CSA was center-mounted (fig. 3). This setup placed the hand controller in a position between the pilot's legs similar to that of the large displacement stick controllers nominally associated with fighter aircraft. The software deadband and stick gearing were left unchanged from the standard F/A-18 configuration.
The control grip, or ministick, used position feedback as the control variable with the pivot point just below the handgrip in the pedestal. For roll control, the grip pivoted approximately $7^{\circ}$ left and right. For pitch control, the ministick could be deflected $7^{\circ}$ forward and $15^{\circ}$ aft, with an increase in force gradient at approximately $11^{\circ}$. For standard flight control operations, the pitch and roll commands were transmitted to the flight control computers as modulated high-frequency AC signals.

The baseline roll stick software deadbands were 0.025 inches (in.) for the F/A- 18 and $0.20^{\circ}$ for the Gripen. Software scaling matched full stick deflections of the ministick with full-scale deflections of the standard F/A-18 control stick ( $\pm 7^{\circ}$ of ministick equalled \pm 3 in. of standard F-18 stick). With the scaling described, the Gripen roll deadband equates to $0.086 \mathrm{in}$.

Figure 4 compares the approximate gearing for the roll stick as a percentage of full stick deflection. The baseline pitch stick software deadbands are $0.060 \mathrm{in}$. for the F/A-18 and $0.20^{\circ}$ for the Gripen. With the scaling described above for full-scale pitch deflections, the Gripen pitch deadband equates to 0.071 in. The approximate gearing for the pitch stick was not compared, because the Gripen uses a normal acceleration command while the F/A-18 uses a command of blended pitch rate and normal acceleration. 


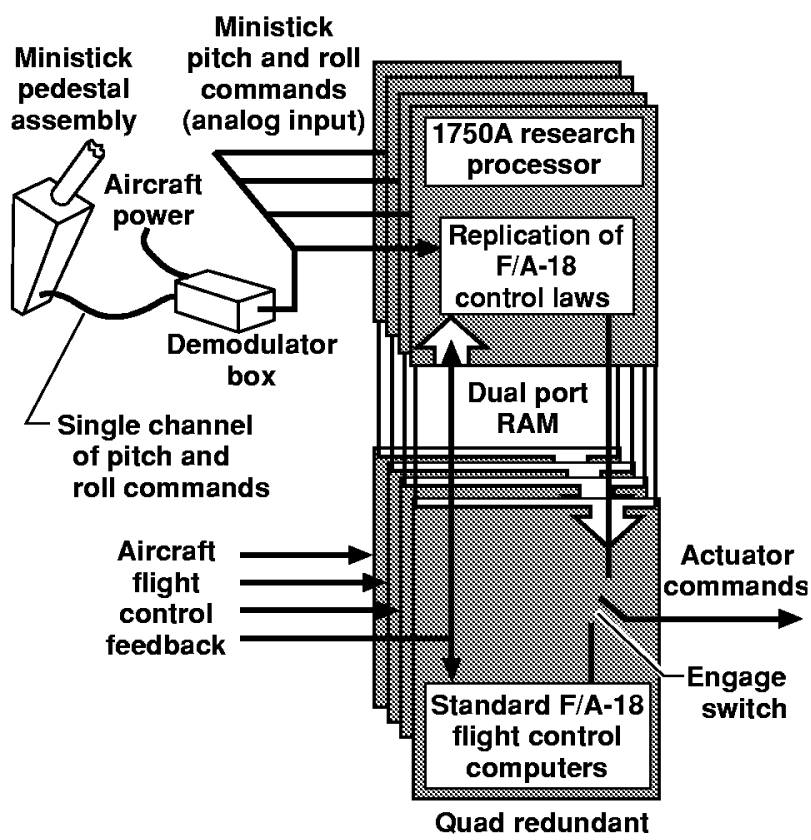

flight control computers

000103

Figure 2. Engaged ministick system.

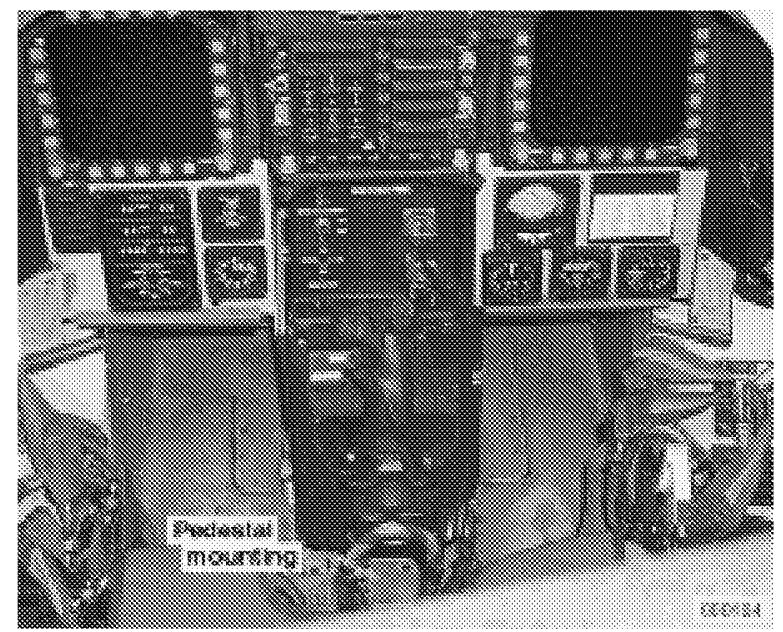

Figure 3. Gripen stick installation.

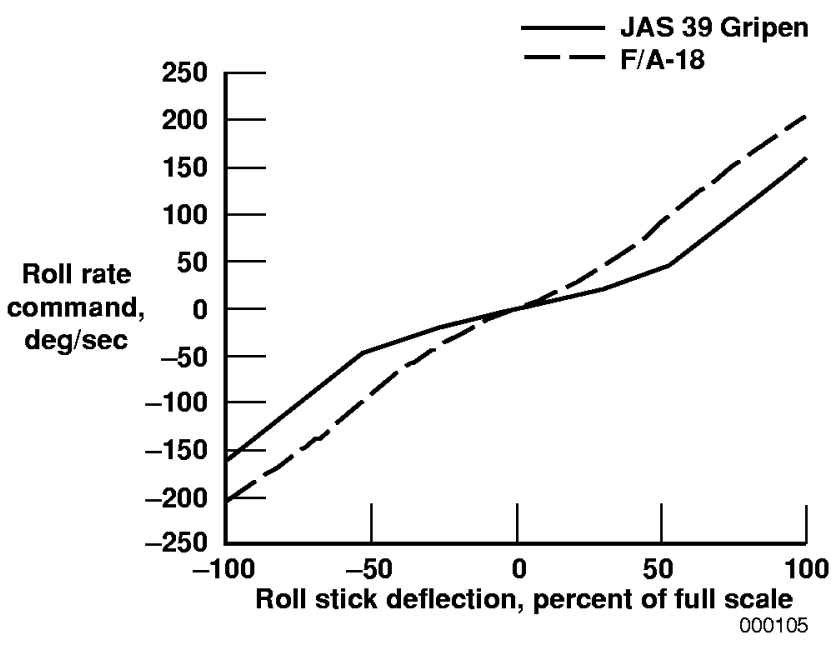

Figure 4. Comparison of stick gearing for roll commands for the Gripen and F/A-18. 
For this experiment, researchers used a demodulator box to read a single channel of the three high-frequency AC signals for pitch and roll commands and to convert it into a DC signal. This resulted in the roll command being scaled to -3.55 volts direct current (VDC) for full left stick and +3.63 VDC for full right stick. In the pitch axis, full forward stick resulted in a signal $-3.56 \mathrm{VDC}$. Full aft stick resulted in a +7.78 VDC signal. Analog inputs sent these single-channel signals to all four channels of the F/A-18 flight control system.

\section{Flight Test Procedure}

The six flights performed between February 23 and March 2, 1999 used five pilots to conduct the evaluation. Telemetered data included aircraft surfaces, rates, accelerations, Euler angles, angle of attack, and health and status of the aircraft and PSFCC system. Strip charts displayed parameters for aircraft dynamics, and computer display pages in the control room displayed parameters for aircraft and PSFCC system status.

Formation flying criteria used visual features of the lead aircraft, such as maintaining the formation flying light of the lead aircraft within the blue stripe on the fuselage of the lead aircraft. For the tracking tasks, a transparency attached to the inside center of the front cockpit canopy of the test aircraft, was just above the helmet of the front pilot. This transparency had two concentric ovals that, when mounted at an angle on the front canopy, appeared circular. Figure 1 shows the position of this simulated gunsight. The pilots flew these maneuvers with feet on the floor in an attempt to assess only the control stick characteristics.

This evaluation used five pilots who were very experienced in F/A-18 aircraft. They also had experience flying the F-16 aircraft, which is equipped with a sidestick controller. All five had extensive experience with handling qualities flight test, including CHRs. All pilots had extensive experience tracking targets from the rear cockpit of an F/A-18. Two pilots had flown direct duplicates of the maneuvers in this program from the rear cockpit of standard F/A-18 aircraft. One pilot had flown the JAS 39 Gripen aircraft.

Because the research flight control system software was not designed to meet flight-critical reliability standards, the flight test could only be performed at relatively low dynamic pressure conditions. All study maneuvers were planned for 0.60 Mach at 27,500 feet (ft).
For the initial engagement flight, each pilot flew buildup activities such as engagement/disengagement checks and gentle maneuvering. After flying an initial engagement, each pilot flew maneuvers (such as doublets, bank angle captures, and pitch angle captures) to become familiar with the characteristics of the stick.

\section{Flight Test Execution}

The following information is from transcriptions of the pilot comments from the mission flight recordings for each maneuver. Some information was lost because sections of the voice recordings were difficult to understand. Selected pilot comments provide comparisons and correlation between the CHRs and the handling qualities analyses. The pilots used the questionnaire in table 1 to generate the handling qualities ratings. CHRs 1,2 , and 3 indicate level 1 handling qualities. This level is characterized by flying qualities clearly adequate for the designed task, using only minimal compensation. CHRs 4,5 , and 6 indicate level 2 handling qualities. These handling qualities are adequate to accomplish the designed task, but with an increase in pilot workload, or decrease in task effectiveness, or both. CHRs 7, 8, and 9 indicate level 3 handling qualities, with excessive pilot workload or inadequate task effectiveness, or both. ${ }^{5}$

Pilot E made the following comment about the installation of the Gripen stick as related to a standard F/A-18 stick:

"Okay, stick installation, for me, is about six inches farther forward than normal and looks like. it has about 5 to 7 degrees of excessive forward tilt for perfect position for me. My arms are a little bit overextended. And also, I'm having to raise my ejection seat up higher than I would to get an adequate arm rest. The shape of the stick conforms naturally to the hand. It's a modern shape, different from a normal $F-18$, with support for the base of the thumb and I find that to be an enhancing characteristic."

\section{Echelon Formation Flight}

\section{Maneuver Description}

After the pilots conducted some familiarization maneuvers and flying qualities tasks, they performed echelon tracking. The maneuvers were made in loose parade position (the approximate position of a \#3 aircraft). The test pilot visually lined up the wingtip and fuselage of the lead aircraft to complete the tasks. The 
Table 1. Cooper-Harper rating scale.

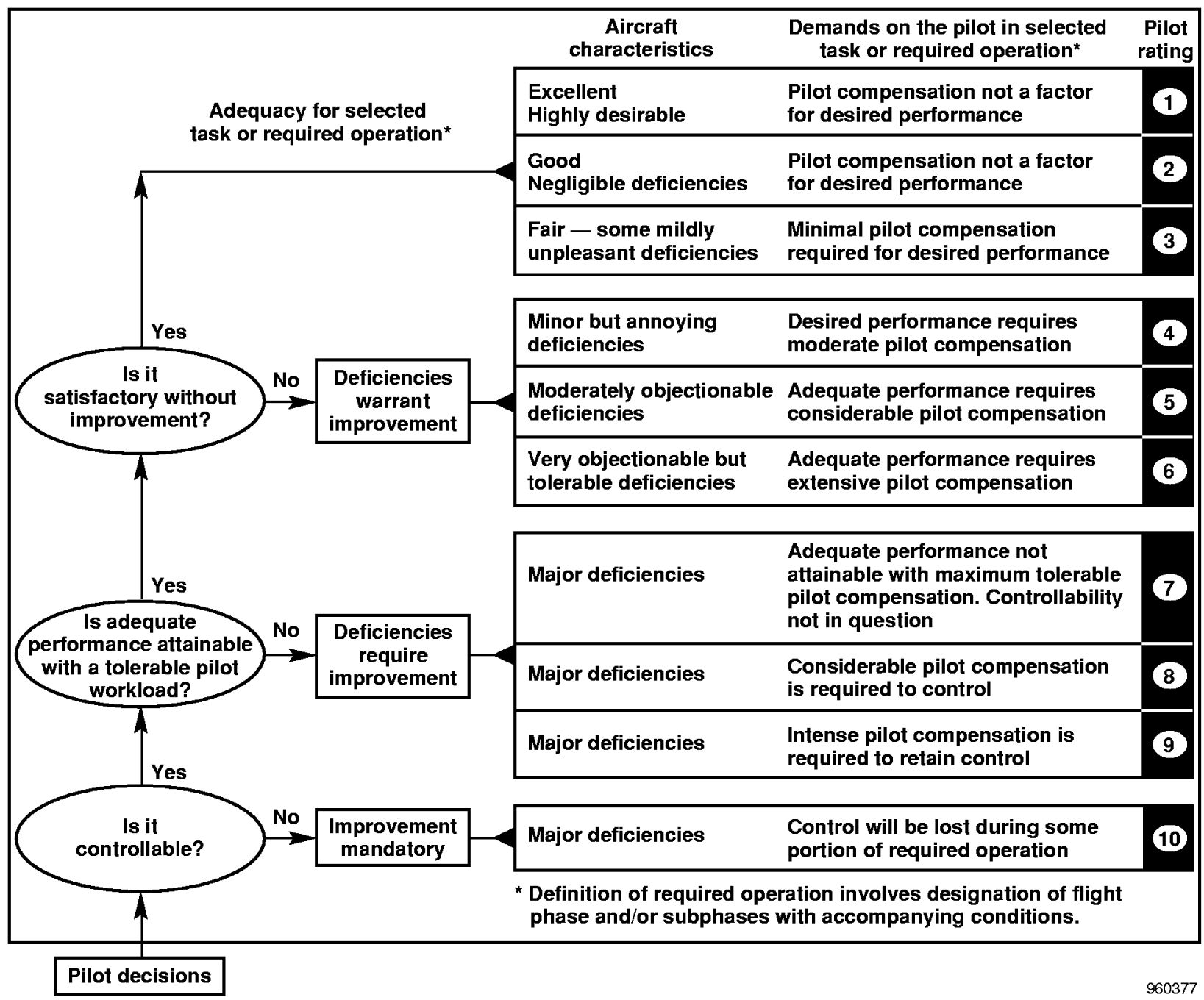

vertical reference was the wingtip formation light vertically centered within the blue fuselage striping (fig. 1). The horizontal references were to align the forward tip of the missile rail with the tip of the lead aircraft radome and the aft tip of the lead aircraft missile rail with the aft red ejection seat warning decal. This results in approximately $15 \mathrm{ft}$ of separation. Altitude was maintained between 15,000 and $32,000 \mathrm{ft}$, and airspeed was maintained between 160 and 250 knots calibrated airspeed (KCAS). The three maneuvering phases for echelon formation flight are as follows:

1. Lead aircraft starts from straight and level and continues with gentle maneuvering of up to $30^{\circ}$ bank and $\pm 30^{\circ}$ pitch.
2. Tracking aircraft starts from straight and level, offset $10 \mathrm{ft}$ downwards, then aggressively captures the formation position.

3. Lead aircraft starts from straight and level and continues with maneuvering up to $90^{\circ}$ bank angle and $\pm 30^{\circ}$ pitch angle.

Adequate and desired criteria were as follows:

- Desired: Maintain the formation light within blue stripe for $5 \mathrm{sec}$.

- Adequate: Maintain the formation light within vertical fuselage limits for $5 \mathrm{sec}$.

Table 2 tabulates CHRs for each pilot using the criteria above in conjunction with the questionnaire from table 1 . 
Table 2. Echelon formation CHRs.

\begin{tabular}{lccccc}
\hline \hline Pilot & $\mathrm{A}$ & $\mathrm{B}$ & $\mathrm{C}$ & $\mathrm{D}$ & $\mathrm{E}$ \\
\hline $\begin{array}{l}\text { Echelon } \\
\text { formation } \\
\text { phase } 1\end{array}$ & 4 & 2 & 2 & 3 & 3 \\
$\begin{array}{l}\text { Echelon } \\
\text { formation } \\
\text { phase } 2\end{array}$ & 6 & 3 & 3 & 5 & 4 \\
$\begin{array}{l}\text { Echelon } \\
\text { formation } \\
\text { phase } 3\end{array}$ & 4 to 7 & 4 & 2 & 5 & 5 \\
\hline \hline
\end{tabular}

Comments

Apparently the pilots could perform the phase 1 tasks without difficulty. One pilot commented on roll sensitivity, giving a CHR of 4 . None of the pilots reported any pitch and roll cross axis coupling of the aircraft for this task.

Pilot B was very satisfied with the ergonomics of the stick, and the ability to control the airplane for this task:

"...You really lose track of the stick in the sense of you just think the airplane around and I have no, no comments on the stick in the negative sense. So I could smoothly fly the airplane and achieve, certainly achieve desired performance. I was happy with the ergonomics of the stick in the sense. of where it is in the cockpit and so on. So I can, as I said before, lose myself and fly ..."

During phase 2, pilot ratings reflected some level 2 handling qualities with CHRs of 4 through 6 . Extensive compensation was required for the task in the pitch axis. Some pilots noticed an abruptness in roll as well.

The pilot comments indicated that it was possible to improve performance to desired levels based on learning from repeated maneuvering and extensive compensation. The pilots noted that aggressiveness affected performance. One pilot made a comparison of formation flight with other aircraft. The pilot comments also noted an appreciation for the position displacement and feedback from this controller, as opposed to fixed, force-sensing control sticks.

Pilot A stated:

“... Okay that was pretty aggressive, I was probably 15 to 20 feet low and I had two overshoots and exceeded the limit, the fuselage. But now I've got it steady within desired criteria. I'll move back down. ... Just putting the missile rail just above the canopy. ... trying to be very aggressive with it, I had one overshoot. Got adequate criteria and now easily, pretty easy to capture and fly standard desired...I got adequate. criteria there, but that was pretty aggressive. I'd give that a 6 for the extensive compensation."

Pilot C stated:

“... The airplane pitches rather abruptly, then moves up and needs to have the nose pushed back over. However, on the third attempt, there was dramatic learning between the first, second, and third attempt. And the third attempt, I was able to maintain desired criteria with essentially no overshoot. The final attempt was a very aggressive. manewver, and I was able to bring it up and stay in desired criteria. There is a little tendency to bobble. Very similar to most of the other formation airplanes we have out here. Certainly reminiscent of both F/A-18s, the F-15B, and the F-16. I think it's certainly satisfactory. Control forces are. acceptably low. And I like the little bit of movement to give you feedback on how much pitch input you've made. Overall, I think the stick, ergonomically, is pretty well put together."

Pilot E commented:

“... Aggressiveness effects, definitely if you were more aggressive, there's no question that that would potentially force you into an overshoot. But definitely, if you're more aggressive than you would under normal instrument formation position conditions, that's going to cause overshoots, probably driving you to adequate rather than desired performance."

Although this task was designed to evaluate pitch axis performance, there was a significant comment regarding abruptness and initial acceleration in the roll axis. Figure 4 shows that the baseline F/A-18 stick gearing results in a steeper slope for roll rate command versus stick deflection than the slope for the Gripen. Because this flight experiment was an evaluation of the mechanical characteristics of the ministick, software deadband and gearing were not changed. A slight adjustment to the roll stick gearing might have corrected the noted abruptness without significantly affecting the performance. 
Pilot B stated:

“... The one thing that I do notice is just the initial acceleration in roll. It's quite high and so you notice that abruptness. You see it every once in while when you' re doing even the pitch things..."

Phase 3 pilot comments ranged from level 1 to level 3, with the majority of the ratings being level 2 . This maneuver required control in both the pitch and roll axes. The one level 3 rating was for the pitch portion of the task. Again, the pilots commented on the initial and undesirable acceleration in roll. The spatial positioning of the aircraft also affected the ability to perform the task. As the lead aircraft was maneuvering, the chase aircraft had to roll and vertically translate the aircraft to maintain proper spacing, because of the relative lever arm between the aircraft.

Pilot A said:

“... we are out here on a long lever arm so if he's rolling with that much time in between, we can't really achieve even adequate criteria. If I had 5 or 10 seconds in there of constant rate or near constant angle of bank, it's easy to get in there. and get desired performance. You're still working reasonably to do it. So ..., I'd still keep the 4 rating. And for verticals it's up to 7 , but simply kind of due to the nature of the task..."

Pilot B noted:

"... I can be very smooth with the exception of the sense that there's this initial acceleration lurking there in the roll...."

\section{Column Formation Flight}

\section{Maneuver Description}

Column formation flight maneuvers were performed aligned with the longitudinal axis of the lead aircraft, with $10 \mathrm{ft}$ of vertical separation and $15 \mathrm{ft}$ nose-to-tail separation. Altitude was between 15,000 and $32,000 \mathrm{ft}$, and airspeed was between 160 and $250 \mathrm{KCAS}$. The three phases of column formation flight were as follows:

1. Lead aircraft starts from straight and level and continues with gentle maneuvering of up to $30^{\circ}$ bank and $\pm 30^{\circ}$ pitch.

2. Lead aircraft increases maneuvering to include up to $45^{\circ}$ bank angle. Random roll input steps are permissible with greater than $15 \mathrm{sec}$ between inputs.
3. Lead aircraft flies straight and level. Test aircraft offsets laterally to align with aileron/flap junction of the lead aircraft. Test aircraft aggressively captures a lateral position aligned with the center of the opposite aileron.

Adequate and desired criteria for phases 1 and 2 were as follows:

- Desired: Maintain lateral position within the limits of the fuselage for $5 \mathrm{sec}$.

- Adequate: Maintain lateral position within the limits of the wingspan for $10 \mathrm{sec}$.

Adequate and desired criteria for phase 3 were as follows:

- Desired: Maintain lateral position within the limits of the aileron-flap junction with one overshoot.

- Adequate: Maintain lateral position with no more than one overshoot, or any displacement greater than one aileron span beyond the wingtip or aileron-flap junction.

\section{Comments}

Pilots gave level 1 and level 2 CHRS for all phases of the column maneuvering, which table 3 shows. For these tasks, the pilots were more emphatic in the comments on roll ratcheting and abruptness in roll. Some abruptness in roll can be attributable to the difference between the baseline software deadband $(0.025$ in.) and the rescaled Gripen deadband ( 0.086 in.). A better matching of these values probably would have reduced the abruptness noted by the pilots. One pilot did notice cross axis coupling. The pilot comments also reflected the ability to learn from repeated maneuvers and apply compensation and change piloting techniques to improve performance.

Table 3. Column formation flight CHRs.

\begin{tabular}{lccccc}
\hline \hline Pilot & $\mathrm{A}$ & $\mathrm{B}$ & $\mathrm{C}$ & $\mathrm{D}$ & $\mathrm{E}$ \\
\hline $\begin{array}{l}\text { Column } \\
\text { formation } \\
\text { phase 1 }\end{array}$ & 4 & 2 & 4 & 3 & 4 \\
$\begin{array}{l}\text { Column } \\
\text { formation } \\
\text { phase } 2\end{array}$ & 3 & 2 & 4 & 3 & 5 \\
$\begin{array}{l}\text { Column } \\
\text { formation } \\
\text { phase } 3\end{array}$ & 3 to 4 & 5 & 4 & 5 & 4 \\
\hline \hline
\end{tabular}


Pilot E stated:

"...the only thing that I really noticed was that the if I failed to pay any attention, I got a little bit of roll ratcheting in there, or roll bobble. Very sensitive there, in terms of roll acceleration. ... And the compensation was for hand position. And an awareness as you initiated manewvers, or did initiated reversals that the airplane is abrupt in roll and you could easily cause a little bit of acceleration. So you have to work to be smooth but you can do it."

Pilot A said:

“... All in all, this seems like an easier task than the echelon, because when you roll, it's a lot easier for me to roll quickly. ... During the phase 2 , it seems obviously more abrupt than front seat maneuvering."

Additionally, one pilot compensation technique was to change the hold on the handgrip. By relaxing grip on the stick and flying with fingertips, the pilot could compensate for some of the undesirable characteristics that had been noticed.

Pilot E noted:

“... There was some awareness of control motion in there, especially if I tried to be abrupt. I tended to grip the stick more and I could sense when I was moving it. I don't like that. And also there was some cross axis coupling as I attempted to be smooth in roll. When you put in a little bit of a pitch change on top of that sometimes that excited a little bit of a smooth but perceptible pitch bobble... both in terms of hand position, the grip on the stick, and the technique that was used in the requirement to back off the performance to compensate for the superimposed small bank angles..."

\section{Target Tracking}

\section{Maneuver Description}

The final target-tracking task used the F/A-18 chase aircraft as a target. The initial setup placed the two aircraft at the abeam position at $220 \mathrm{KCAS}$ and an altitude greater than $20,000 \mathrm{ft}$ mean sea level. At "cleared to maneuver" call, the target aircraft began a military power 2 to $3 \mathrm{~g}$ normal acceleration turn away from the test aircraft. The test aircraft pilot would aggressively maneuver to perform a gross acquisition and tracking task. After the test aircraft called "tracking," the target was cleared to increase the severity of maneuvering. Altitude was maintained between 15,000 and $32,000 \mathrm{ft}$, and airspeed was maintained between 160 and $250 \mathrm{KCAS}$. Criteria for gross acquisition and fine tracking provided a reference for pilot comments and ratings.

As discussed earlier, the tracking task was performed using concentric ovals on a transparency attached to the front cockpit as a gunsight. The oval placement in the aircraft resulted in a positive depression angle for the gunsight, possibly resulting in a slight "pendulum effect." Because the ovals were at an angle to the flightpath angle of the aircraft, they moved in a conical motion as the aircraft rolled, resulting in more lateral movement than a gunsight reticle would exhibit for the same maneuver. When interviewed, however, the pilots felt that this movement was not significant for this flight program.

Gross acquisition adequate and desired criteria were as follows:

- Desired: Maintain lateral position within large oval with one or no overshoots.

- Adequate: Maintain lateral position within large oval with two or fewer overshoots.

Tracking adequate and desired criteria were as follows:

- Desired: Maintain the target aircraft within inner oval for $5 \mathrm{sec}$.

- Adequate: Maintain the target aircraft within outer oval for $5 \mathrm{sec}$.

Table 4 contains all the CHRs taken during the gross acquisition and fine tracking maneuvers.

Table 4. Tracking CHRs.

\begin{tabular}{lccccc}
\hline \hline Pilot & $\mathrm{A}$ & $\mathrm{B}$ & $\mathrm{C}$ & $\mathrm{D}$ & $\mathrm{E}$ \\
\hline $\begin{array}{l}\text { Gross } \\
\text { acquisition }\end{array}$ & $\mathrm{n} / \mathrm{r}$ & 2 & 2 & 6 to 7 & 4 \\
$\begin{array}{l}\text { Longitudinal } \\
\text { fine tracking }\end{array}$ & $\mathrm{n} / \mathrm{r}$ & 2 & 2 & 3 & 3 \\
$\begin{array}{l}\text { Lateral fine } \\
\text { tracking }\end{array}$ & $\mathrm{n} / \mathrm{r}$ & 2 & 3 & 4 & 6 \\
\hline \hline
\end{tabular}

Comments

Pilot A did not fly the target tracking maneuvers. For the most part, pilots rated this task level 1 . Pilots B and 
C could perform the tasks very easily. The only issue mentioned was some difficulty in tracking laterally. Abruptness in roll acceleration was once again reported to be undesirable and a degrading factor in the ability of the pilots to perform the tasks.

Pilot C noted:

"So, for gross acquisition we were able to meet all the desired criteria with ease. The target comes up and stops. Primarily a pitch manewver and there were no overshoots apparent, stopping inside the oval with ease. Fine tracking both in pitch and ... well starting with pitch, we were able to move the pipper from canopy to the tail pipes with ease. There was no tendency to PIO [pilot induced oscillation] or to overshoot... a little bit of difficulty with the abruptness of the roll acceleration that gave you a little bit, little bit of difficulty in predicting where the pipper was going laterally..."

Pilot D gave CHRs of 6 and 7 for the gross acquisition task because of poor predictability with aggressive maneuvering and some coupling of the pitch and roll axes. Poor control in the yaw axis was also described.

Pilot D said:

"...The difficulty with the gross acquisition is the more aggressive you are with the acquisition, the harder it is to stop the pipper at the point that you want to stop it... What you have to do is back off on your aggressiveness...Okay, on the lateral axis, ... you put your inputs in and it would seem like. the nose would, like the airplane would develop a little yaw or something like that, because you would roll back the other way. But the nose lags, would lag the inputs relatively significantly. Generally, laterally, you'd get much larger overshoots. And it's harder to get back over to where you want it because of this adverse yaw tendency. So the undesirable motion was the adverse yaw, plus it's kind of an abrupt response. on the airplane. So the airplane's kind of wallowing around almost like you could force it into a dutch roll type of motion. The predictability was, I think, poor on that. The difficulty was primarily not so much the lateral axis as it had to do with this kind of coupling into the directional axis. Compensation techniques, you could back off the gains and improve the situation a little bit. Sensitivity was, in the lateral axis, I think it's too sensitive. It needs to be, it needs to be reduced somewhat."
Pilot E gave a CHR of 6 for the lateral fine tracking, resulting from adverse yaw developed during fine lateral inputs. The pilots flew these maneuvers with feet on the floor in an attempt to assess only the control stick characteristics. Pilot E said:

“... Once you go out to the wingtip, and then go from one wing to the other especially, if there's any aggressiveness whatsoever, you tend to get into a lateral oscillation with superimposed adverse yaw on top of it..."

\section{Handling Qualities Analysis}

To analytically assess the potential impacts of the mechanical characteristics of the ministick on the longitudinal dynamics of the F/A-18, an evaluation was conducted using criteria from the military specification MIL-STD-1797. ${ }^{5}$ This military specification provides handling qualities guidelines for piloted vehicles and addresses the CAP and Neal-Smith criteria used in this report. The evaluations below used the transfer function evaluated from pitch stick to pitch response from the flight data, providing an analytical assessment of the handling qualities of the F/A-18. The correlation and analysis of the pilot comments and ratings in conjunction with this assessment were helpful in understanding any variations that might be attributed to the Gripen stick.

The primary consequence of the low cost nature of this project was that the Gripen stick position and the flight control system pitch rate were only recorded at 20 samples per second. Frequency analysis of the Gripen longitudinal stick position to pitch rate was used to estimate the stick position to pitch angle transfer function used with handling qualities techniques presented in MIL-STD-1797.

The frequency response of Gripen stick to pitch rate $(Q)$ was fit into a LOES model. ${ }^{5,9,10}$ Fast Fourier Transform analysis was performed on each of the maneuvers to extract the frequency response data. These models were used to calculate the following parameters for the handling qualities analysis: aircraft short period frequency $(\omega)$ and damping $(\zeta)$, and time delay $(-\tau)$, and static gain $\left(K_{q}\right)$ of the system, using a fixed value for lift due to angle of attack, $L_{\alpha}$. The LOES technique uses an optimization program to fit a frequency response of pitch rate to stick position to a simplified linear model: 


$$
\frac{Q}{\text { stick }}=\frac{K_{q}^{*}\left(s+L_{\alpha}\right)^{*} e^{-\tau s}}{s^{2}+2 \zeta \omega_{s p} s+\omega_{s p}^{2}}
$$

To increase the fidelity of the LOES fit, the $L_{\alpha}$ was calculated from the NASA Dryden nonlinear simulation for each flight condition and fixed in the LOES model.

Figure 5 shows a typical fit of the LOES to a frequency response. The LOES program calculates a cost function to indicate the quality of the flight data match to the LOES model by comparing the differences in gain and phase between the LOES transfer function and the transfer function derived from flight data. The expression for the cost function is as follows:

$$
\text { Cost }=\frac{20}{N O F} \sum\left(\Delta \operatorname{gain}^{2}+0.0175 \Delta p h a s e^{2}\right)
$$

where $N O F$ is the number of frequency points, $\triangle$ gain is the variation between the original and approximated transfer functions, and $\Delta$ phase is the variation between the original and approximated transfer functions.

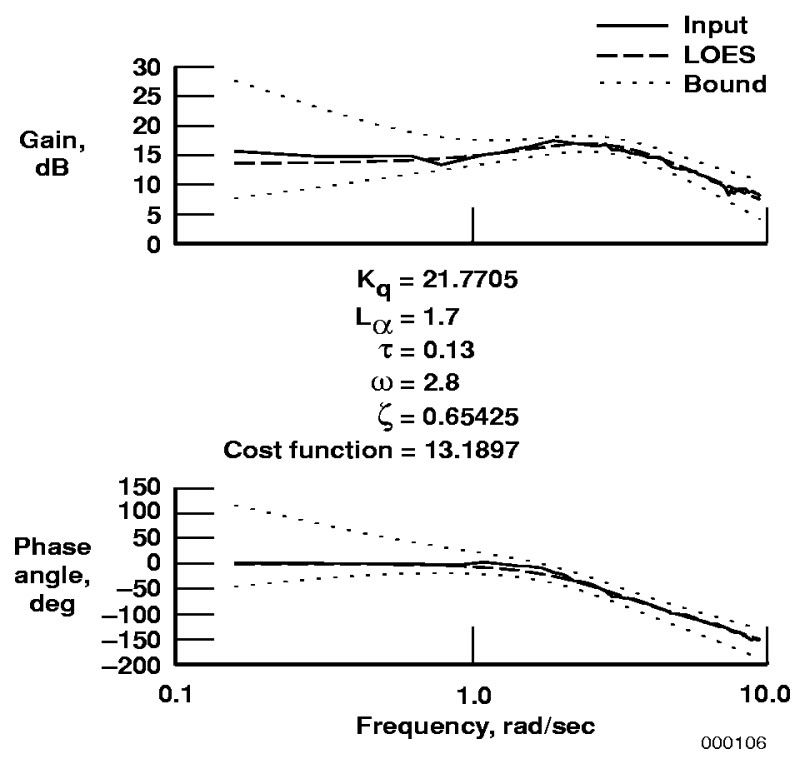

Figure 5. Typical LOES data fit of equation (1).

Table 5 shows the parameters for all of the LOES fits for the handling qualities data taken. The cost numbers ranged from 12 to 972 . The fits were examined, and those that did not reflect a realistic LOES model for the aircraft were not included in analysis.
Figure 6 plots the CAP versus equivalent short period damping ratio. $\mathrm{CAP}$ analysis relates the aircraft short period natural frequency to the acceleration sensitivity. The approximation for CAP is calculated from the following expression:

$$
C A P=\omega_{s p}^{2} /(N z / \alpha)
$$

where $\omega_{s p}$ is the short period natural frequency, $N z$ is the normal load factor, and $\alpha$ is the angle of attack.

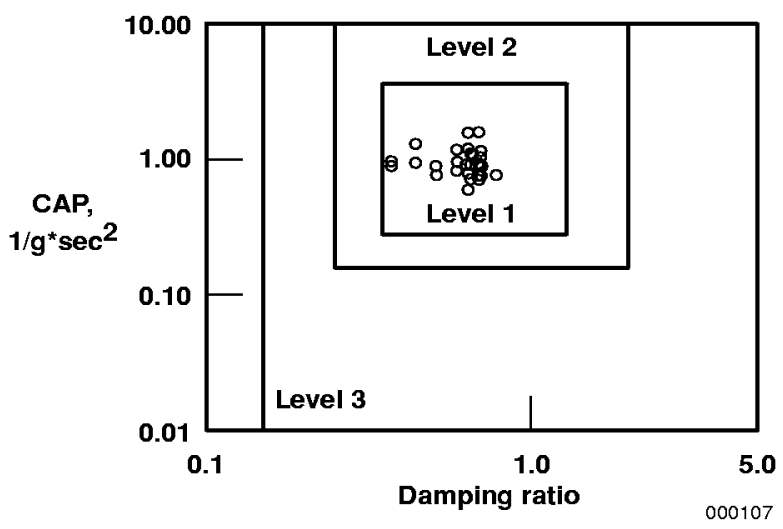

Figure 6. CAP analysis.

The CAP criterion originated for unaugmented aircraft, and analyzes only the dynamics of the aircraft without taking into account the time delay of the aircraft flight control system. This aircraft was evaluated for category A flight phase for class IV aircraft, highmaneuverability fighters. Category $\mathrm{A}$ is defined as nonterminal flight phases that require rapid maneuvering, precision tracking, or precise flight path control. The circles on this figure represent the echelon, column, and tracking maneuvers performed during this flight test. The results indicate that the aircraft should have level 1 handling qualities in pitch for all of the maneuvers included in the analysis.

MLL-STD-1797 also establishes a criterion for equivalent time delay. The specification requires a time delay less than 100 milliseconds (msec) for level 1 and less than $200 \mathrm{msec}$ for level 2 handling qualities. From table 5, most of the calculated time delays range between 110 and $130 \mathrm{msec}$, which are borderline level 1/level 2 values. Five cases meet the level 1 criterion. Two cases have values of $180 \mathrm{msec}$ corresponding with level 2. The comparison of the LOES equivalent time delay values correlates with the pilot ratings and comments. 
Table 5. LOES fits of maneuver data.

\begin{tabular}{|c|c|c|c|c|c|c|c|c|c|}
\hline & $L_{\alpha}$ & $\begin{array}{c}\omega \\
(\mathrm{rad} / \mathrm{sec})\end{array}$ & $\zeta$ & $\begin{array}{c}\tau \\
(\mathrm{sec})\end{array}$ & Cost & $K_{q}$ & CAP & $\begin{array}{l}\text { Neal Smith } \\
\text { lead (deg) }\end{array}$ & $\begin{array}{c}\text { Neal Smith } \\
\text { peak }(\mathrm{dB})\end{array}$ \\
\hline \multicolumn{10}{|c|}{ Echelon 1} \\
\hline Pilot A & 1.80 & 3.1 & 0.65 & 0.12 & 17 & 23.6 & 0.92 & 51.2 & 1.6 \\
\hline Pilot B & 1.89 & 2.6 & 0.78 & 0.11 & 81 & 18.7 & 0.78 & 66.0 & 1.9 \\
\hline Pilot C & 1.73 & 3.0 & 0.70 & 0.11 & 36 & 26.6 & 0.90 & 53.5 & 1.4 \\
\hline Pilot D & 1.72 & 2.8 & 0.65 & 0.13 & 12 & 21.8 & 0.72 & 57.7 & 4.5 \\
\hline Pilot E & 1.97 & 3.3 & 0.66 & 0.12 & 35 & 24.7 & 1.09 & 50.3 & 2.6 \\
\hline \multicolumn{10}{|c|}{ Echelon 2} \\
\hline Pilot A & 2.07 & 3.3 & 0.44 & 0.13 & 72 & 21.8 & 1.31 & 39.2 & 1.9 \\
\hline Pilot B & 1.63 & 2.9 & 0.51 & 0.10 & 49 & 21.6 & 0.77 & 45.0 & 3.3 \\
\hline Pilot C & 1.62 & 2.9 & 0.70 & 0.11 & 35 & 26.7 & 0.76 & 53.8 & 5.5 \\
\hline Pilot D & 1.84 & 3.1 & 0.37 & 0.18 & 189 & 20.3 & 0.96 & 37.4 & 12.9 \\
\hline Pilot E & 1.64 & 3.0 & 0.59 & 0.10 & 23 & 20.7 & 0.83 & 46.5 & 8.1 \\
\hline \multicolumn{10}{|c|}{ Echelon 3} \\
\hline Pilot A & 2.18 & 2.7 & 0.59 & 0.12 & 45 & 17.6 & 0.95 & 63.1 & 2.4 \\
\hline Pilot B & 1.66 & 3.0 & 0.51 & 0.10 & 136 & 18.8 & 0.90 & 42.7 & 1.5 \\
\hline Pilot C & 2.23 & 3.0 & 0.56 & 0,07 & 60 & 21,0 & 1.17 & 51.3 & 5.2 \\
\hline Pilot D & 1.84 & 3.0 & 0.56 & 0.10 & 77 & 18.7 & 0.90 & 48.5 & 3.7 \\
\hline Pilot E & 1.84 & 3.1 & 0.69 & 0.11 & 42 & 23.9 & 0.96 & 52.8 & 4.7 \\
\hline \multicolumn{10}{|c|}{ Column 1} \\
\hline Pilot A & 1.88 & 3.0 & 0.63 & 0.11 & 25 & 23.1 & 0.92 & 52.7 & 2.4 \\
\hline Pilot B & 1.77 & 3.3 & 0.65 & 0.11 & 43 & 17.6 & 1.11 & 45.9 & 1.9 \\
\hline Pilot C & 1.62 & 2.9 & 0.69 & 0.12 & 53 & 22.0 & 0.76 & 54.4 & 1.8 \\
\hline Pilot D & 1.82 & 3.2 & 0.70 & 0.12 & 45 & 22.4 & 1.04 & 51.4 & 1.7 \\
\hline Pilot E & 1.96 & 3.3 & 0.59 & 0.09 & 32 & 18.8 & 1.18 & 44.1 & 2.7 \\
\hline \multicolumn{10}{|c|}{ Column 2} \\
\hline Pilot A & 1.76 & 2.9 & 0.64 & 0.11 & 25 & 23.3 & 0.79 & 54.1 & 2.4 \\
\hline Pilot B & 1.74 & 2.7 & 0.69 & 0.11 & 55 & 17.8 & 0.78 & 59.8 & 1.7 \\
\hline Pilot C & 1.62 & 2.9 & 0.69 & 0.12 & 53 & 22.0 & 0.76 & 54.4 & 2.4 \\
\hline Pilot D & 1.80 & 3.1 & 0.69 & 0.11 & 34 & 22.2 & 0.91 & 51.8 & 3.4 \\
\hline Pilot E & 1.68 & 2.6 & 0.64 & 0.11 & 55 & 18.8 & 0.60 & 60.0 & 2.7 \\
\hline \multicolumn{10}{|c|}{ Column 3} \\
\hline Pilot A & 2.14 & 3.1 & 0.62 & 0.11 & 25 & 22.7 & 1.20 & 54.3 & 3.6 \\
\hline Pilot B & 1.67 & 3.0 & 0.76 & 0.11 & 32 & 22.3 & 0.94 & 54.4 & 2.6 \\
\hline Pilot C & 1.54 & 2.8 & 0.64 & 0.12 & 54 & 20.4 & 0.71 & 53.1 & 0.9 \\
\hline Pilot D & 2.22 & 3.4 & 0.48 & 0.15 & 130 & 22.4 & 1.58 & 44.3 & 6.9 \\
\hline Pilot E & 2.22 & 3.5 & 0.53 & 0.10 & 52 & 18.3 & 1.59 & 41.3 & 2.4 \\
\hline \multicolumn{10}{|c|}{ Tracking } \\
\hline Pilot B & 1.84 & 2.8 & 0.80 & 0.13 & 31 & 22.9 & 0.92 & 63.0 & 2.6 \\
\hline Pilot C & 1.69 & 3.1 & 0.65 & 0.12 & 63 & 24.3 & 0.94 & 49.5 & 1.9 \\
\hline Pilot D & 1.93 & 2.5 & 0.84 & 0.18 & 56 & 20.9 & 0.72 & 73.7 & 2.5 \\
\hline Pilot E & 1.79 & 3.3 & 0.65 & 0.11 & 972 & 13.1 & 1.03 & 45.5 & 5.6 \\
\hline
\end{tabular}


The Neal-Smith criterion ${ }^{6}$ assumes a simple closedloop pitch attitude tracking task; in the task a compensator of predetermined form is used to close the loop around the airframe plus flight control system transfer function for pitch attitude from the control stick $(\theta /$ stick $)$. The compensator is assumed to be of the form:

$$
K_{p} * e^{-\tau_{\text {comp }} s^{*}} \frac{\left(T_{\text {lead }}{ }^{*} s+1\right)}{\left(T_{\text {lag }}{ }^{*} s+1\right)}
$$

where $K_{p}$ is the gain for compensation model, $T_{\text {lead }}$ is the compensator lead time constant, $T_{\text {lag }}$ is the compensator lag time constant, and $\tau_{\text {comp }}$ is the compensator time delay.

The parameters in the model are adjusted to meet the desired closed loop solution of having $90^{\circ}$ of rolloff in the phase angle at the desired bandwidth of $3.0 \mathrm{rad} / \mathrm{sec}^{6,9}$ The relationship between the required phase compensation and resultant resonant peak of the closed loop transfer function can be related to level 1 , level 2, and level 3 handling qualities (fig. 7). Figure 7 also shows circles for handling quality maneuvers flown in this program. The compensator model for this analysis used a time delay $\left(\tau_{\text {comp }}\right.$ ) of $0.3 \mathrm{sec}$. Note that the results of this analysis would predict the CHRs to be in the level 2 area with some of the data on the border of the level 1 region. These results demonstrate that the analysis corresponds substantially with the pilot CHRs.

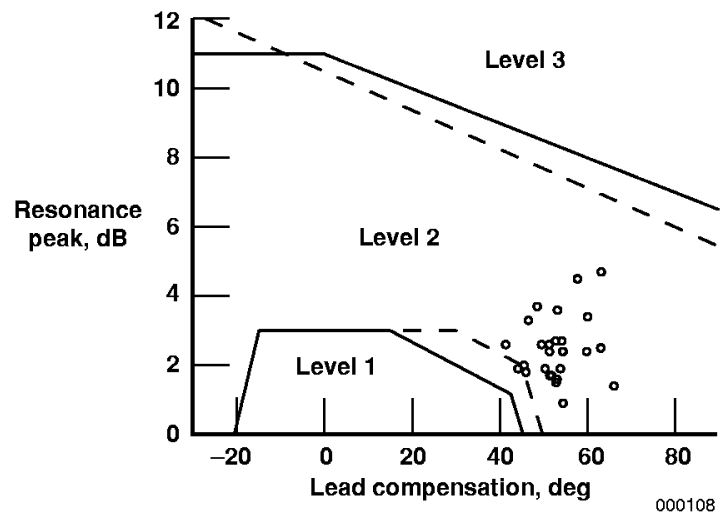

Figure 7. Neal-Smith analysis.

By varying the bandwidth and allowed droop for the closed-loop frequency response in the Neal-Smith criterion, an assessment can be made on the robustness of a predicted handling qualities level. Steep slopes tend to show sensitivity to the pilot technique, or bandwidth a pilot might use to perform certain flying tasks. Analysis is conducted to relate the measured pilot stick activity with the results of the carpet plot.

Figure 8 shows a Neal-Smith "carpet" plot based on a representative case from figure 7 . This plot is constructed by varying bandwidth for the criterion between 2.5 and $4.0 \mathrm{rad} / \mathrm{sec}$, while simultaneously allowing the low frequency droop to vary by \pm 0.5 decibels $(\mathrm{dB})$. This carpet shows an area of pilot ratings that can be obtained by assuming that variations in compensator bandwidth can be correlated with pilot stick activity. The predicted CHRs for the representative compensator model with a bandwidth of $3 \mathrm{rad}$ and a time delay of $0.3 \mathrm{sec}$ would be in the lower portion of level 2 bordering the level 1 region, suggesting a CHR of 4. As the modeled compensator bandwidth increases, the handling quality predictions move from level 1 to level 2 to level 3 . If the compensation has a bandwidth or activity greater than the baseline value, the CHR will move along the solid line on the carpet plot toward level 3.

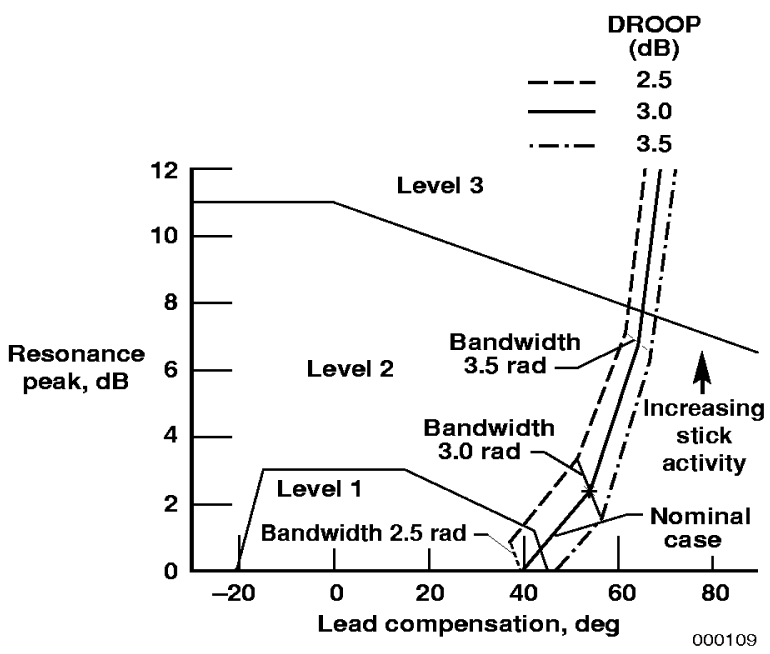

Figure 8. Neal-Smith carpet plot of representative case.

For the echelon phase 3 task, Pilot A gave a CHR of 7 (level 3) to the vertical position capture task, (refer to echelon phase 3 comments and table 2). Pilots B, C, D, and $\mathrm{E}$ gave ratings of $4,2,5$, and 5 (level 1/level 2 ratings), respectively, for the same task. Figure 9 shows a power spectral density of the pitch stick activity for the gross acquisition and tracking task. Pilot A had significantly more high-frequency stick activity than pilots $B, C, D$, and $E$ had. This higher frequency activity is indicative of a pilot with a bandwidth greater than the 
compensator used for the Neal-Smith analysis. As the Neal-Smith carpet indicates, this greater bandwidth could cause the pilot to be well into handling quality levels 2 or 3 , and possibly a CHR of 7 .

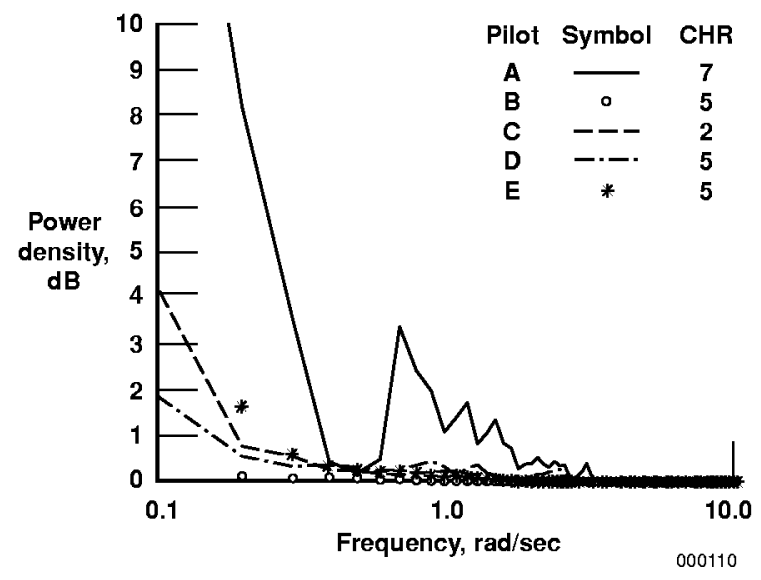

Figure 9. Power spectral density of echelon phase 3.

\section{Summary}

A six-flight program evaluated whether the mechanical characteristics of the Gripen small displacement control stick affected the handling qualities of an F/A-18 aircraft. Production support flight control computers (PSFCC) supported this effort. NASA Dryden installed the Gripen hardware in the aft cockpit of a two-place F/A-18. The analog inputs of the PSFCCs connected the pitch and roll commands from the Gripen control stick to the baseline F/A-18 control laws in the research processor. The flight program demonstrated the suitability of the PSFCCs for this type of flight research.

Five pilots evaluated both open-loop maneuvers such as doublets, and closed-loop maneuvers such as bank angle and pitch angle captures, echelon formation flight, column formation flight, and target tracking. CooperHarper ratings (CHR) and pilot comments were collected. The ratings and comments from the closedloop tasks were used for the handling qualities evaluation.

Pilot comments indicate that no serious handling quality deficiencies resulted from the installation or mechanical characteristics of the Gripen stick. Handling quality analysis was performed using the flight data. Low order equivalent system (LOES) model fits provided estimated values for short-period frequency, short-period damping, time delay, and transfer function gain using fixed $L_{\alpha}$. These values were used with control anticipation parameter and Neal-Smith analyses to determine the handling qualities of the airframe independent of the Gripen control stick. The control anticipation parameter analysis indicated that the aircraft should have level 1 handling qualities, while the Neal-Smith analysis indicated that the aircraft should have borderline level 1/level 2 or level 2 handling qualities, which corresponded with the majority of pilot comments and ratings.

The LOES data show good comparison with the criterion for equivalent time delay of $100 \mathrm{msec}$ for level 1 and $200 \mathrm{msec}$ for level 2. Most of the cases have equivalent time delays between 110 and $130 \mathrm{msec}$; this finding is consistent with borderline level 1 and level 2 handling qualities.

Overall, the pilot ratings and comments correlated well with the Neal-Smith analysis with a bandwidth of $3.0 \mathrm{rad} / \mathrm{sec}$. Most ratings for a wide range of tasks were level 2. A few borderline level 1 and level 2 CHRs were given. One noticeable exception was a CHR of 7 (level 3) given by one pilot for vertical motion during the echelon phase 3. Power spectral density analysis showed that this pilot had significantly more stick activity than the other pilots, which is correlated with performing the closed-loop task at a higher bandwidth. The Neal-Smith carpet plot correlated with the comments and rating given by this pilot. This analysis shows that a higher bandwidth for the closed-loop task would result in degraded handling qualities.

Pilots with F-16 flying experience used F-16 flying techniques such as loosening their grip on the control stick in higher gain maneuvers. Many pilots used very loose grips while controlling with the Gripen stick, some using only three fingers to hold the top of the control stick while maneuvering.

The pilots did notice an abruptness in initial roll response for small amplitude inputs. The software deadbands and stick shaping used with the Gripen stick were not modified from the standard F/A-18 software. Tuning of the deadband and the stick gearing more closely to the mechanization of the Gripen stick could lead to better pilot ratings for the gross acquisition task. These software changes could also have addressed the pilot comments on abruptness and roll acceleration sensitivity. Pilots also commented on poor yaw control. Allowing the use of the rudder pedals during maneuvering flight could have controlled this deficiency. 
Pilot comments demonstrated an ability to easily control the airplane. The pilot comments were favorable with respect to the motion feedback provided by the Gripen controller as opposed to the lack of feedback in force-command sidestick controllers.

\section{$\underline{\text { References }}$}

${ }^{1}$ Hall, G. Warren and Rogers E. Smith, Flight Investigation of Fighter Side-Stick Force-Deflection Characteristics, AFFDL-TR-75-39, May 1975.

${ }^{2}$ Carter, John F., Production Support Flight Control Computers: Research Capability for F/A-18 Aircraft at Dryden Flight Research Center, NASA TM-97-206233, 1997.

${ }^{3}$ Cooper, George E. and Robert P. Harper, Jr., The Use of Pilot Rating in the Evaluation of Aircraft Handling Qualities, NASA TN D-5153, 1969.

${ }^{4}$ Mitchell, David G. and Roger H. Hoh, "Low-Order Approaches to High-Order Systems: Problems and Promises," AIAA-81-1774, Aug. 1981.
${ }^{5}$ U.S. Air Force, Flying Qualities of Piloted Vehicles, MIL-STD-1797, Mar. 31, 1987.

${ }^{6}$ Bailey, Randall E. and Rogers E. Smith, "Analysis of Augmented Aircraft Flying Qualities Through Application of the Neal-Smith Criterion," AIAA-811776, Aug. 1981.

${ }^{7}$ Sitz, Joel, F-18 Systems Research Aircraft Facility, NASA TM-92-4433, 1992.

${ }^{8}$ Carter, John F. and Mark Stephenson, Initial Flight Test of the Production Support Flight Control Computers at NASA Dryden Flight Research Center, NASA TM-1999-206581, 1999.

${ }^{9}$ Stoliker, P. C., High-Angle-of-Attack Handling Qualities Predictions and Criteria Evaluation for the $X-31 A$, NASA TM-4758, 1997.

${ }^{10}$ Hodgkinson, John, "Equivalent Systems Criteria for Handling Qualities of Military Aircraft," AGARD Conference Proceedings No. 333, June 1982. 
Public reporting burden for this collection of information is estimated to average 1 hour per response, including the time for reviewing instructions, searching existing data sources, gathering and maintaining the data needed, and completing and reviewing the collection of information. Send comments regarding this burden estimate or any other aspect of this collection of information, including suggestions for reducing this burden, to Washington Headquarters Services, Directorate for Informatıon Operations and Reports, 1215 Jefferson Davis Highway, Suite 1204, Arlington, VA 22202-4302, and to the Office of Management and Budget, Paperwork Reduction Project (0704-0188), Washington, DC 20503.

1. AGENCY USE ONLY (Leave blank)

2. REPORT DATE

3. REPORT TYPE AND DATES COVERED

August 2000

Technical Memorandum

4. TITLE AND SUBTITLE

Flying Quality Analysis of a JAS 39 Gripen Ministick Controller in an

F/A-18 Aircraft

6. AUTHOR(S)

WU $5296114 \mathrm{M} 10014000 \mathrm{~S} 000$

John F. Carter and P. C. Stoliker

7. PERFORMING ORGANIZATION NAME(S) AND ADDRESS(ES)

NASA Dryden Flight Research Center

P.O. Box 273

Edwards, California 93523-0273

8. PERFORMING ORGANIZATION

REPORT NUMBER

H-2418

9. SPONSORING/MONITORING AGENCY NAME(S) AND ADDRESS(ES)

10. SPONSORING/MONITORING AGENCY REPORT NUMBER

National Aeronautics and Space Administration

Washington, DC 20546-0001

NASA/TM-2000-209024

11. SUPPLEMENTARY NOTES

Presented at AIAA Guidance Navigation and Control Conference, Denver, Colorado, August 14-17, 2000, AIAA-2000-4444.

12a. DISTRIBUTION/AVAILABILITY STATEMENT

12b. DISTRIBUTION CODE

Unclassified-Unlimited

Subject Category 08

This report is available at http://www.dfrc.nasa.gov/DTRS/

13. ABSTRACT (Maximum 200 words)

NASA Dryden conducted a handling qualities experiment using a small displacement centerstick controller that Saab-Scania developed for the JAS 39 Gripen aircraft. The centerstick, or ministick, was mounted in the rear cockpit of an F/A-18 aircraft. Production support flight control computers (PSFCC) provided a pilotselectable research control system. The objectives for this experiment included determining whether the mechanical characteristics of the centerstick controller had any significant effect on the handling qualities of the F/A-18, and determining the usefulness of the PSFCCs for this kind of experiment. Five pilots evaluated closed-loop tracking tasks, including echelon and column formation flight and target following. Cooper-Harper ratings and pilot comments were collected for each maneuver. This paper describes the test system, including the PSFCCs, the Gripen centerstick, and the flight test experiment. The paper presents results of longitudinal handling qualities maneuvers, including low order equivalent systems, Neal-Smith, and controls anticipation parameter analyses. The experiment showed that, while the centerstick controller provided a different aircraft feel, few handling qualities deficiencies resulted. It also demonstrated that the PSFCCs were useful for this kind of investigation.

\section{SUBJECT TERMS}

Aircraft control, Flight control, Handling qualities, JAS 39 Gripen, Piloting

17. SECURITY CLASSIFICATION
OF REPORT
Unclassified

18. SECURITY CLASSIFICATION
OF THIS PAGE
Unclassified

Unclassified

19. SECURITY CLASSIFICATION
OF ABSTRACT
Unclassified

Unclassified
15. NUMBER OF PAGES

21

16. PRICE CODE

A03

20. LIMITATION OF ABSTRACT

Unlimited

Standard Form 298 (Rev. 2-89) Prescribed by ANSI Std. Z39-18 298-102 